\title{
Role of haemolytic and non-haemolytic phospholipase C from Pseudomonas aeruginosa in interleukin-8 release from human monocytes
}

\author{
B. KÖNIG, M. L. VASIL* and W. KÖNIG
}

Medizinische Mikrobiologie und Immunologie, AG Infektabwehr, Ruhr-Universität Bochum, D-44780 Bochum, Germany and *Department of Microbiology and Immunology, University of Colorado Health Sciences Center, Denver, Colorado, USA

\begin{abstract}
A massive accumulation of neutrophils, mainly due to enhanced interleukin-8 (IL-8) levels, is believed to contribute to the deleterious effects of Pseudomonas aeruginosa lung infection, e.g., in cystic fibrosis (CF). Antibodies to phospholipase $C$, an exoenzyme of $\boldsymbol{P}$. aeruginosa, are detected early and at high levels in CF patients. However, $P$. aeruginosa produces at least two types of phospholipase C (PLC), one haemolytic (PLC-H) and the other non-haemolytic (PLC-N), both with mol. wts of c. $77 \mathrm{kDa}$. Experiments were performed to evaluate the potential contribution of $P$. aeruginosa PLC to neutrophil accumulation during infection. Therefore, $P$. aeruginosa PLC-H and PLC-N were compared with regard to IL-8 generation from human monocytes. Purified PLC-H as well as culture supernates (mol. wt $>50 \mathrm{kDa}$ ) of a $P$. aeruginosa strain capable of producing both PLC-H and PLC-N, and mutant strains deficient in the production of one or other phospholipase, or both, were examined. Purified PLC-H (only at low concentrations up to 1 unit $/ 4 \times 10^{5}$ monocytes), induced a dose-dependent increase in IL-8 release and IL-8-specific mRNA expression over that of unstimulated cells (at 4-, 12- and 24-h incubation times). Higher concentrations of PLC-H led to a decrease in IL8 release and IL-8-specific mRNA expression. These findings were confirmed by the results obtained with the supernates of cultures of mutant strains of $P$. aeruginosa PAO1 that produced either a PLC-H or PLC-N or neither. Stimulation and inhibition of IL-8 release and mRNA expression were associated with a culture supernate fraction of mol. wt $>50 \mathrm{kDa}$ and containing PLC-H. These results contribute to the understanding of the role of both $P$. aeruginosa PLC in IL-8 generation during their interaction with human monocytes.
\end{abstract}

\section{Introduction}

Pseudomonas aeruginosa infections play an important role in burns and sepsis, as well as in cystic fibrosis (CF) $[1-3]$. In contrast to acute $P$. aeruginosa infections in burned patients, CF patients become chronically colonised by $P$. aeruginosa [3-5]. The pathogenesis of CF injury is associated with a massive accumulation of neutrophil granulocytes and neutrophil-mediated chronic pulmonary inflammation and destruction $[4,6,7]$. Although elevated levels of leukotriene $B_{4}-$ a potent chemotactic factor for neutrophils - have been found in the sputum of CF patients, it is now well established that the chemotactic cytokine

Received 11 April 1996; revised version accepted 23 Oct. 1996.

Corresponding author: Professor W. König. interleukin-8 (IL-8) is probably the main cause of the excessive neutrophil recruitment and activation because of its long-lasting effect $[6,8-10]$.

P. aeruginosa produces various virulence factors. Phospholipase $\mathrm{C}$, an exoenzyme of $P$. aeruginosa, has been identified as a critical component in the pathogenesis of $P$. aeruginosa infection [11-13]. Antibodies to phospholipase $\mathrm{C}$ are detected early and at high levels in CF patients $[14,15]$. However, $P$. aeruginosa produces at least two types of phospholipase C (PLC), one haemolytic (PLC-H) and the other non-haemolytic (PLC-N) [16-18]. The PLC-H with a mol.wt of $77 \mathrm{kDa}$ haemolyses human and sheep erythrocytes and degrades not only phosphorylcholine but also sphingomyelin, which are key components of eukaryotic cell membranes. PLC-N, with a mol. wt of c. $78 \mathrm{kDa}$, is non-haemolytic for red blood cells and does not degrade sphingomyelin [16-18]. 
Supernates of bacterial cultures of $P$. aeruginosa containing PLC induced the generation of the chemotactic active leukotriene $\mathrm{B}_{4}$ from human neutrophils and monocytes [2]. Similar results were obtained with partially purified PLC as described by Meyers et al. in in-vivo and in-vitro models [12]. The role of $P$. aeruginosa PLC in IL-8 generation has not been studied yet. Furthermore, previous studies did not distinguish between the two types of PLC with regard to their interaction with human effector cells. Current investigations regarding PLC activity by Pseudomonas have adopted a genetic approach. In this regard, the results of Graham et al. suggest that it is predominantly PLC-H that plays a role in the inflammation in the model of chronic lung infection in the rat $[18,19]$. Studies performed by Wiener-Kronish et al. with isogenic $P$. aeruginosa PAO1 strains indicated that PLC is predominantly important in mediating injury to the alveolar epithelial barrier in acute $P$. aeruginosa pneumonia in rabbits [7]. PLC production enhanced virulence when tested in a model of burns in the mouse $[7,16]$.

The present study was designed to evaluate the relative inabilities of PLC-H and PLC-N to induce IL-8 release from human monocytes - the main producers of IL- 8 . The study used several previously characterised isogenic $P$. aeruginosa PAO1 strains that were deficient in the production of either PLC-H or PLC-N, or both; purified haemolytic PLC from $P$. aeruginosa was also used.

\section{Materials and methods}

\section{Materials}

Peptone, sodium metrizoate solution $(75 \% \mathrm{w} / \mathrm{v})$ and RPMI medium 1640 (no. 430-1800) were obtained from Gibco (Eggenstein, Germany). Additional chemicals were obtained from Sigma. The IL-8 antibodies were kindly provided by M. Ceska, Sandoz, Vienna, Austria.

\section{Buffer}

The buffer used for washing the peripheral blood mononuclear cells (PBMC) and monocytes was modified Dulbecco's phosphate-buffered saline (PBS) containing $137 \mathrm{mM} \mathrm{NaCl}, 8 \mathrm{mM} \mathrm{Na}_{2} \mathrm{HPO}_{4}, 3 \mathrm{mM} \mathrm{KCl}$ and $3 \mathrm{mM} \mathrm{KH}_{2} \mathrm{PO}_{4}, \mathrm{pH} 7.4$. For stimulation assays the cells were suspended in RPMI 1640 medium supplemented with fetal calf serum (FCS) $10 \%$.

\section{Bacterial strains}

The bacterial strains used in the study are listed in Table 1. P. aeruginosa PAO1, expressing both PLC-H and PLC-N, was used as the wild-type strain. The following mutants were used. P. aeruginosa $\mathrm{PAO} \Delta \mathrm{SR}$ is a deletion mutant that retains PLC-N when measured
Table 1. Bacterial strains studied

\begin{tabular}{lcc}
\hline Strains & $\begin{array}{c}\text { Type of } \\
\text { phospholipase C } \\
\text { produced }\end{array}$ & References \\
\hline$P$ aeruginosa PAOl wild-type & PLC-H; PLC-N & $16-18$ \\
$P$. aeruginosa PAO1 $\triangle \mathrm{SR}$ & PLC-N & $16-18$ \\
$P$ a aeruginosa $\mathrm{PAO1}$ PLCN & PLC-H & $16-18$ \\
$P$. aeruginosa PAO1 $\triangle \mathrm{SRN}$ & None & $16-18$ \\
\hline
\end{tabular}

on the synthetic substrate nitrophenylphosphorylcholine. In PAO1 PLCN ${ }^{\circ}$ only the gene PLC-N has undergone mutation; the PLC-H was still detectable. The double deletion mutant of PAO1, PAO1 $\triangle \mathrm{SRN}$, in which both PLC structural genes have been deleted, lacked any detectable PLC activity in the nitrophenylphosphorylcholine assay [16-18].

\section{Bacterial growth and isolation of culture supernates}

Bacteria were cultured in peptone medium $(\mathrm{NaCl} 1 \%$, peptone $1 \%$, glycerol $1 \%$ ). Tetracycline was added at a concentration of $20 \mu \mathrm{g} / \mathrm{ml}$ for $P$. aeruginosa strains PAO1 $\triangle$ SR and PAO1 $\triangle$ SRN. Ten $\mathrm{ml}$ of broth were inoculated with $100 \mu \mathrm{l}$ of an overnight culture of the appropriate $P$. aeruginosa strain and incubated with shaking $(180 \mathrm{rpm})$ at $30^{\circ} \mathrm{C}$ for $20-24 \mathrm{~h}$ until the early stationary growth phase. The culture supernates were filter sterilised and used at the indicated dilutions.

\section{Preparation of $P$. aeruginosa culture supernate fractions}

P. aeruginosa PAO1 or the PAO1 mutants were cultured in phosphate-deficient peptone medium [20] to induce the synthesis of PLC. Bacterial cells were removed by centrifugation $(5000 \mathrm{~g}, 10 \mathrm{~min}$; Sorvall RC-5B, rotor SS34) and the supernate was filter sterilised. Twenty $\mathrm{ml}$ of the original culture supernate (100 mM HEPES, $500 \mathrm{mM} \mathrm{NaCl}, 1 \mathrm{mM} \mathrm{CaCl}_{2}, \mathrm{pH} 7.5$ ) were concentrated to $2 \mathrm{ml}$; the original volume was made up with buffer and again concentrated. This procedure was carried out three times. The resulting solution was considered as 'undiluted'. To achieve the various culture supernate fractions concentrators (Centriplus ${ }^{\mathrm{TM}}$, Amicon $\mathrm{GmbH}$, Witten, Germany) with mol. wt cut-offs of 50, 30 and $5 \mathrm{kDa}$ were used. The culture supernate above $50 \mathrm{kDa}$ contained PLC activities as indicated in the Results section. The concentrated culture supernate fractions were stored at $4^{\circ} \mathrm{C}$.

\section{Preparation of purified P. aeruginosa PLC-H}

PLC-H was produced for purification by overexpression of the $p l c H$ gene in a $\mathrm{T} 7$ expression system constructed for $P$. aeruginosa [21]. Cultures of $P$. aeruginosa ADD1976 (pADD3268:plcH) were grown in brain-heart infusion media to an $\mathrm{OD}_{600}$ of $c .0 .4$, $1 \mathrm{mM}$ IPTG was added to induce expression and 
incubation was continued for $20 \mathrm{~h}$. Bacteria were removed by centrifugation and $25 \mathrm{~g}$ of Whatman D52 anion exchanger washed in Tris buffer containing $50 \mathrm{mM} \mathrm{NaCl}, 50 \mathrm{~mm}$ Tris-HCl, pH 7.5 (Whatman Int., Maidstone) was added to each litre of supernate and the suspension was stirred overnight at $4^{\circ} \mathrm{C}$. The DE52 with adsorbed protein was then collected by filtration, and washed twice with Tris buffer. Bound protein was eluted by two washes of buffer containing $500 \mathrm{mM} \mathrm{NaCl}, 50 \mathrm{~mm}$ Tris- $\mathrm{HCl}, \mathrm{pH} 7.5$, and then concentrated with $\left(\mathrm{NH}_{4}\right)_{2} \mathrm{SO}_{4} 70 \% \mathrm{w} / \mathrm{v}$ precipitation. The precipitate was collected by centrifugation and resuspended in Tris buffer. For final purification, portions of the concentrated protein solution were subjected to preparative gel electrophoresis with a BioRad model 491 electrophoresis apparatus (BioRad, Melville, NY, USA). Samples of the resuspended precipitate were resolved under conditions specified by the manufacturer, and collected fractions were examined for PLC-H activity. Several fractions containing the highest amount of PLC activity were pooled and analysed further. Five $\mu \mathrm{g}$ of protein from the pooled fractions as determined by absorbance at $280 \mathrm{~nm}$ were analysed by SDS-PAGE. Only a single band of $78 \mathrm{kDa}$ was seen on the Coomassie-stained gel. The activity of PLC in the phosphatidylcholine assay, the haemolytic activity of PLC on human erythrocytes and the toxicity of PLC towards 3T3 fibroblasts cells (ATCC CLL 92) grown to confluence of this preparation were completely abolished by heating the PLC preparation at $100^{\circ} \mathrm{C}$ for $5 \mathrm{~min} ; 100 \mathrm{ng}$ of $\mathrm{PLC}-\mathrm{H}$ was lethal for the $3 \mathrm{~T} 3$ cells. No endotoxin was found to be associated with $1 \mu \mathrm{g}$ of the pure PLC-H as determined by the Quantitative Chromogenic Limulus Amebocyte Lysate Assay (BioWhittaker, Walkersville, MD, USA).

\section{Enzyme assays}

The activity of PLC was determined spectrophotometrically $\left(\mathrm{OD}_{420} \mathrm{~nm}\right)$ with $p$-nitrophenylphosphorylcholine as substrate [20]. One unit of activity (U) was defined as the amount of enzyme necessary to liberate $1 \mu \mathrm{mol}$ of $p$-nitrophenol/min from $p$-nitrophenylphosphorylcholine at $37^{\circ} \mathrm{C}$

\section{Preparation of monocytes}

Human peripheral blood mononuclear cells (PBMC) were isolated by Ficoll-Hypaque sedimentation from venous blood anti-coagulated with ethylenediaminetetraacetic acid [22]. The isolated PBMC contained $c$. $15 \%$ monocytes as estimated by the non-specific esterase assay [23]. PBMC were incubated at a concentration of $1 \times 10^{7} / \mathrm{ml}$ at $37^{\circ} \mathrm{C}$ in air with $\mathrm{CO}_{2}$ $5 \%$ in plastic flasks (Costar) for $2 \mathrm{~h}$. The adherent cells were collected and $95 \%$ of the cells were esterasepositive by the esterase assay according to the method of Tucker et al. [23].

\section{Cell viability}

Cell viability was studied by trypan blue exclusion, by analysis of lactate dehydrogenease (LDH) release (Boehringer Mannheim, Mannheim, Germany), as well as by determination of mitochondrial activity with WST-1 (Boehringer Mannheim) in stimulated and unstimulated cells. The assays were performed as described by the manufacturer. All cellular stimulation experiments were performed under conditions of concentration and time in which the viability of the monocytes in all three assay systems was $>80 \%$.

\section{Cell culture conditions}

Monocytes were suspended in RPMI medium plus FCS $10 \%$ at a concentration of $4 \times 10^{5} / \mathrm{ml}$. The cells were cultured in the presence of the appropriate stimulus for up to $24 \mathrm{~h}$. Culture supernates were collected and analysed for their IL-8 content; cell pellets were analysed for IL-8-specific mRNA expression.

\section{IL-8 assay}

IL-8 release was determined by a sandwich ELISA technique as described previously [24]. Briefly, each well of a 96-well plate (Nunc Maxisorb, Roskilde, Denmark) was pre-coated overnight at $4^{\circ} \mathrm{C}$ with $100 \mu \mathrm{l}$ of Tween $200.1 \%$ in PBS containing a monoclonal anti-IL-8 antibody (subclone 4G9/A5/A7) at a concentration of $5 \mu \mathrm{g} / \mathrm{ml}$. The plates were washed three times with PBS/Tween, the appropriate samples and the standard (a recombinant human IL-8; Calbiochem, Bad Soden, Germany) were added and incubation proceeded for $2 \mathrm{~h}$ at $37^{\circ} \mathrm{C}$. Thereafter, polyclonal antiIL-8 antibody labelled with alkaline phosphatase $(3 \mu \mathrm{g} / \mathrm{ml})$ was added. After addition of $p$-nitrophenylphosphate $(15 \mathrm{mg} / 10 \mathrm{ml})$ an ELISA reader read the colour development and Mikrotek software (SLT Labinstruments, Crailsheim, Germany) was used to calculate the concentrations.

\section{Detection of IL-8 mRNA expression by PCR}

Total RNA was extracted from $4 \times 10^{5}$ cells with Trizol reagent (Gibco). Total RNA was analysed in $20 \mu \mathrm{l}$ of $\mathrm{H}_{2} \mathrm{O}$. Expression of IL-8-specific mRNA was analysed after reverse transcription with oligo(dT) and PCR amplification of the cDNA transcripts. The reverse transcription step and the amplification steps were performed with M-MLV reverse transcriptase (Gibco) and Taq-Polymerase transcriptase (Gibco) according to the manufacturer's instructions. The primers were as follows: sense, 5'CTTAGATGTCAGTGCATAAAGACATACTCC-3'; antisense, 5'CTCAGCCCTCTTCAAAAACTTCTCCACA-3'.

\section{Statistical analysis}

Unless stated otherwise, all data show mean values and $\mathrm{SD}$ of at least three individual experiments with cells 
from different donors. Significance was examined by Student's $t$ test for independent means.

\section{Results}

Modulation of IL-8 synthesis by purified PLC-H from $P$. aeruginosa

In a first set of experiments the capacity of purified PLC-H from $P$. aeruginosa to modulate IL-8 release from human monocytes was examined. Human monocytes $\left(4 \times 10^{5}\right)$ were stimulated with various concentrations of purified PLC-H at concentrations of 10,5 , 2.5, 1 and $0.2 \mathrm{U}$ for $2,4,12$ and $24 \mathrm{~h}$ at $37^{\circ} \mathrm{C}$. The results are presented in Fig. 1 for IL- 8 release and in Fig. 2 for IL-8-specific mRNA expression, both for an incubation time of $24 \mathrm{~h}$. The data indicate that purified PLC-H exerts stimulatory as well as suppressive effects on the secretion and expression of IL-8 and IL-8 mRNA from human monocytes as measured by ELISA and RT-PCR. These effects were most pronounced after an incubation time of $24 \mathrm{~h}$ (kinetics not shown). In this

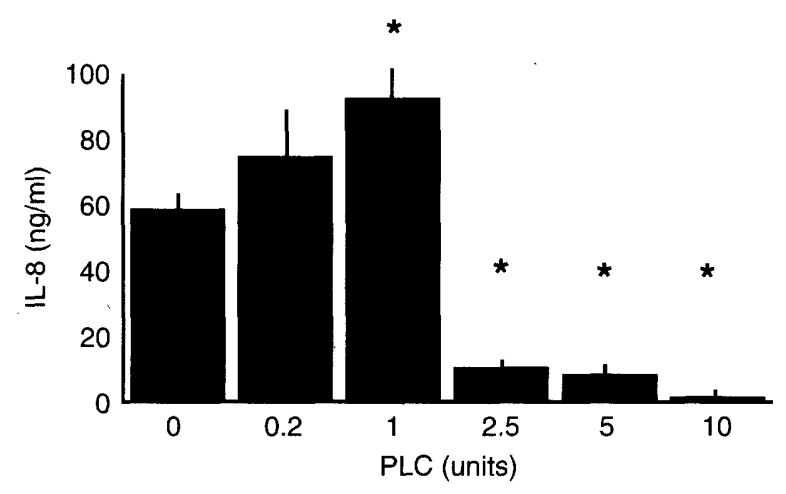

Fig. 1. Effects of purified $P$. aeruginosa haemolytic phospholipase $\mathrm{C}$ on $\mathrm{IL}-8$ release $(\mathrm{ng} / \mathrm{ml})$ from human monocytes $\left(4 \times 10^{5} / \mathrm{ml}\right)$ stimulated with purified PLC from $P$. aeruginosa at the indicated concentrations for $24 \mathrm{~h}$. Data are mean and SD from three independent experiments; *significant difference compared to unstimulated human monocytes ( 0 U PLC), $\mathrm{p}<0.05$.

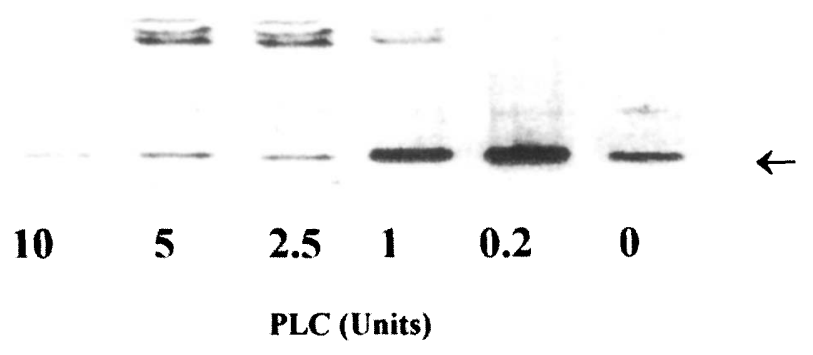

Fig. 2. Effects of purified $P$. aeruginosa haemolytic phospholipase $C$ on IL-8 mRNA expression in human monocytes $\left(4 \times 10^{5} / \mathrm{ml}\right)$ stimulated with purified PLC from $P$. aeruginosa at the indicated concentrations for $24 \mathrm{~h}$. One typical experiment out of four independent experiments is shown. The arrow indicates the IL-8specific product amplified by PCR. regard PLC-H at low concentrations of 0.2 and $1 \mathrm{U} / 4 \times 10^{5}$ monocytes led to an increase in IL-8 release from human monocytes by up to $20 \mathrm{SD} 4 \%$; maximal induction of IL-8 was given by $1 \mathrm{U}$ PLC (Fig. 1, p < 0.05). The results were confirmed by the mRNA level as shown in Fig. 2. Suppression of IL-8 production was detected at PLC levels above $1 \mathrm{U}$ for PLC-H.

\section{$I L-8$ release from monocytes after stimulation with $P$. aeruginosa culture supernates}

Both PLC-H and PLC-N were present in the culture supernates of $P$ aeruginosa strains. To clarify their roles in IL-8 release from human monocytes, 10-fold concentrated culture supernates with a mol.wt $>$ $50 \mathrm{kDa}$ from $P$. aeruginosa PAO1 wild-type strain as well as from PAO1 mutants that express only PLC-N (PAO1 $\triangle \mathrm{SR}$ ), only PLC-H (PAO1 $\mathrm{PLCN}^{\circ}$ ) or no PLC $(\mathrm{PAO} 1 \triangle \mathrm{SRN})$ were used. Human monocytes $\left(4 \times 10^{5}\right)$ were left untreated or were treated with dilutions of the appropriate culture supernates from undiluted ( 1 in 1) to dilutions of 1 in 2,1 in 5,1 in 10,1 in 100 for 2,4 and $24 \mathrm{~h}$. The respective PLC activities of the undiluted and diluted culture supernate were $6,3,1,0.5$ and $0.05 \mathrm{U}$ for PAO1 and for PAO1 $\triangle \mathrm{SR}, 3,1,0.5,0.1$ and $0.05 \mathrm{U}$ for PAO1 $\mathrm{PLCN}^{\circ}$, and no PLC activity for PAO1 $\triangle$ SRN. Fig. 3 shows the results after an incubation time of $24 \mathrm{~h}$ : only culture supernates expressing PLC-H (PAO1 and PAO1 $\mathrm{PLCN}^{\circ}$ ) led to a decrease in IL-8 release (Fig. 3a). In parallel to the decrease in IL-8 release a decrease in IL-8-specific mRNA expression (Fig. 3b) was observed in the corresponding monocyte pellets. The decrease in IL-8 production was observed in a time- and dose-dependent manner. In this regard, culture supernates containing PLC-H at concentrations $>1 \mathrm{U}$ (PAO1 and PAO1 $\mathrm{PLCN}^{\circ}$ ) diminished spontaneous IL-8 release; $3 \mathrm{U}$ PLC-H of PAO1 $\mathrm{PLCN}^{\circ}$ reduced release to $0.6 \mathrm{SD}$ $0.3 \mathrm{ng} / \mathrm{ml}$ compared with $78 \mathrm{SD} 12 \mathrm{ng} / \mathrm{ml}$ from unstimulated cells. The inhibitory effects of PLC-H were observed after an incubation time of $4 \mathrm{~h}$ and were most pronounced after an incubation time of $24 \mathrm{~h}$ (Fig. 4). The data are presented for P. aeruginosa PAO1 in Fig. 4a and for $P$. aeruginosa PAO1 $\mathrm{PLCN}^{\circ}$ in Fig. $4 \mathrm{~b}$. In contrast to those containing PLC-H, culture supernates containing only PLC-N (PAO1 $\Delta$ SR), even at the high concentration of $7 \mathrm{U}$, neither downregulated nor upregulated IL-8 release from human monocytes (data not shown). Culture supernates devoid of PLC activity (PAO1 $\triangle S R N$ ) also failed to modulate IL-8 release (data not shown).

\section{Modulation of IL-8 release from human monocytes after stimulation with different fractions of $P$. aeruginosa culture supernates}

The ability of additional exoproducts of $P$. aeruginosa to modulate IL-8 release from human monocytes was tested. For this purpose total culture supernates from 


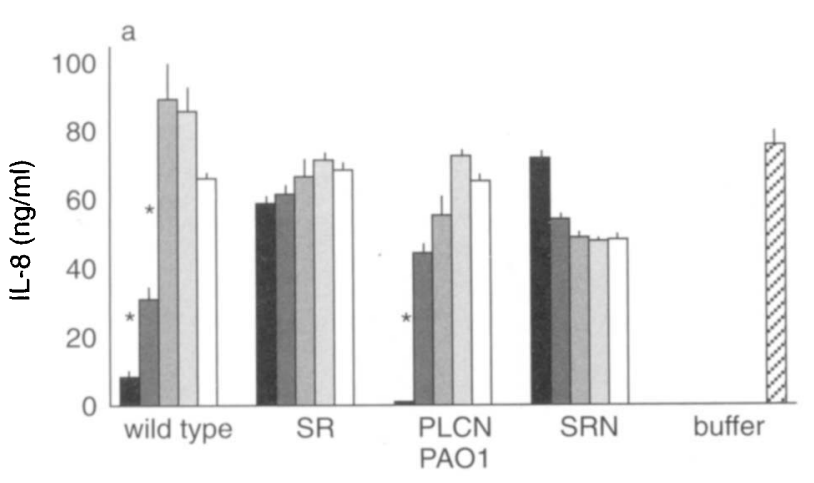

b

\section{PAO1 $\triangle$ SRN}

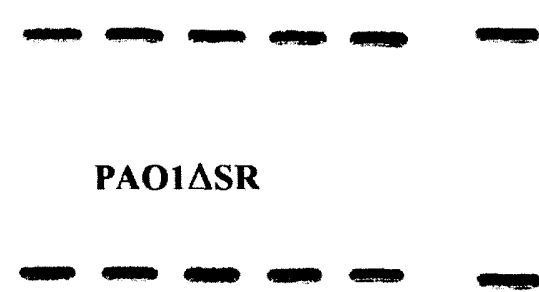

PAOI PLCN

\section{PAO1}

\section{1:1 1:2 1:5 1:10 1:100 control}

Fig. 3. Dose-dependent effects of haemolytic and nonhaemolytic phospholipase C on IL-8 release from human monocytes $\left(4 \times 10^{5}\right)$ left untreated (unstimulated cells, (Z), or cultured with undiluted $(1: 1, \mathbf{\square})$ or with diluted $(1: 2,1: 5,1: 10,1: 100 ; \square, \square, \square, \square)$ culture supernate (mol. wt cut-off $>50 \mathrm{kDa}$ ) of the appropriate $P$. aeruginosa strains (PAO1, PAO $\triangle \mathrm{SR}, \mathrm{PAO} 1 \mathrm{PLCN}^{\circ}$, $\mathrm{PAO} \triangle \mathrm{SRN}$ ). The respective PLC activities were $6,3,1$, 0.5 and $0.05 \mathrm{U}$ for PAO1 and for PAO1 $\triangle \mathrm{SR} ; 3,1.5,0.5$, 0.1 and $0.01 \mathrm{U}$ for PAO1 PLCN ${ }^{\circ}$; and no PLC activities for PAOI $\triangle \mathrm{SRN}$. The culture supernates and the cell pellets (monocytes) were isolated after $24 \mathrm{~h}$. Supernates were assayed for IL- 8 by ELISA (a) and the cell pellets for IL-8-specific mRNA expression (b). Data are mean and SD from three independent experiments; * significant difference compared to unstimulated cells, $\mathrm{p}<0.05$.

PAO1 as well as from the PAO1 mutants were fractionated and concentrated by ultrafiltration with defined filter pore sizes. Human monocytes $\left(4 \times 10^{5}\right)$ were stimulated with different dilutions ranging from
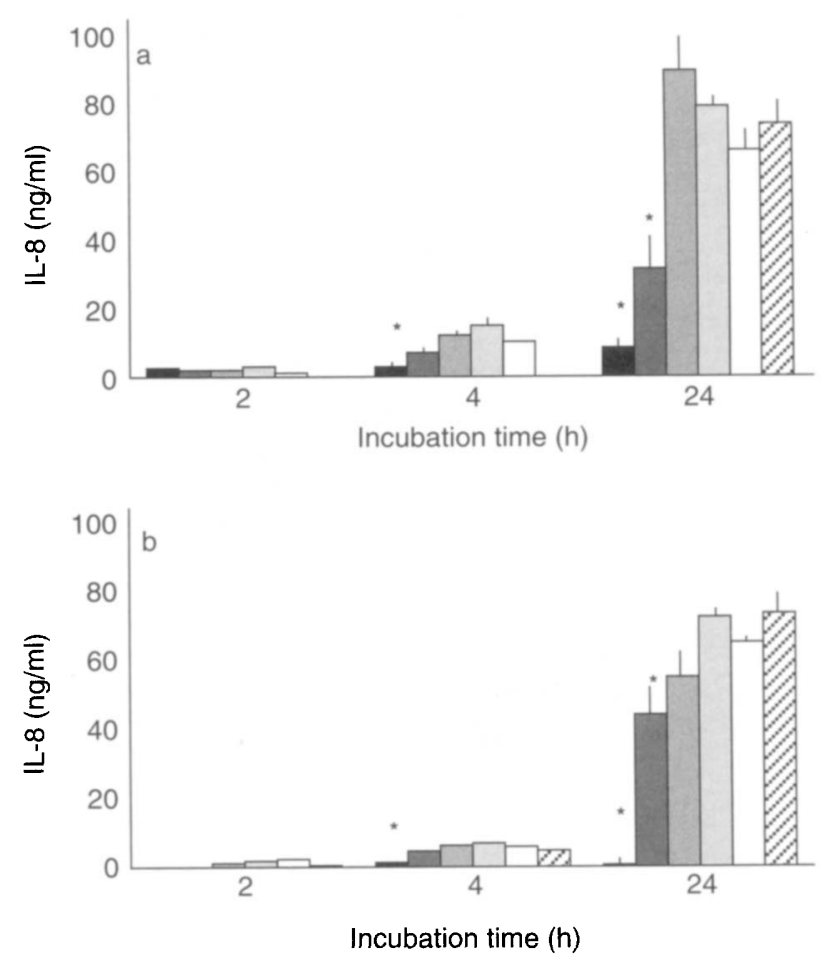

Fig. 4. Time-dependent effect of haemolytic and nonhaemolytic phospholipase $C$ on IL-8 release from human monocytes $\left(4 \times 10^{5}\right)$ left untreated (unstimulated cells, G) or cultured with undiluted $(1: 1 ; \square)$ or with diluted $(1: 2,1: 5,1: 10,1: 100 ; \mathbf{\square}, \mathbf{\square}, \square, \square)$ culture supernate (mol. wt cut-off $>50 \mathrm{kDa}$ ) of (a) P. aeruginosa PAOl and (b) PAO PLCN ${ }^{\circ}$. The respective PLC activities were $6,3,1,0.5$ and $0.05 \mathrm{U}$ for PAO1 and $3,1,0.5,0.1$ and $0.01 \mathrm{U}$ for PAO1 $\mathrm{PLCN}^{\circ}$. The culture supernates were isolated after 2, 4 and $24 \mathrm{~h}$ and assayed for IL-8 by ELISA (triplicate determination). Data are mean and SD from five independent experiments; *significant difference compared to unstimulated cells, $\mathrm{p}<0.05$.

undiluted ( 1 in 1$)$ to 1 in 100 of the various fractions that contained components $>50 \mathrm{kDa} ; 30-50 \mathrm{kDa} ; 5-$ $30 \mathrm{kDa}$ and $<5 \mathrm{kDa}$ for $2,4,12$ and $24 \mathrm{~h}$. The respective PLC values for the fractions above mol. wt $50 \mathrm{kDa}$ were $6,3,1,0.5$ and $0.05 \mathrm{U}$ for PAO1 and for PAO $\triangle S R ; 3,1.5,0.5,0.01$ and $0.01 \mathrm{U}$ for PAO1 PLCN ${ }^{\circ}$; PAO1 $\triangle S R N$ showed no PLC activity. The fractions with components below $50 \mathrm{kDa}$ showed no PLC activities. For an incubation time of $24 \mathrm{~h}$, only the fractions with components $>50 \mathrm{kDa}$ from PAO1 (Fig. 5a) and PAO1 PLCN ${ }^{\circ}$ (Fig. 5b), but not from PAO1 $\triangle$ SR (Fig. 5c) or PAO1 $\triangle$ SRN (Fig. 5d), modulated IL-8 release from human monocytes. Similar results were obtained for incubation times $<24 \mathrm{~h}$ (data not shown). Thus, LPS (a stimulus for IL-8 release) was absent or a minor component in the culture supernates from the early stationary phase. The inhibitory effects on IL-8 release were not due to an increase in trypan blue staining, $\mathrm{LDH}$ release or a decrease in mitochondrial activity. The results of determination of IL-8-specific MRNA expression also showed modulation by components $>50 \mathrm{kDa}$ from PAO1 (Fig. 6). 

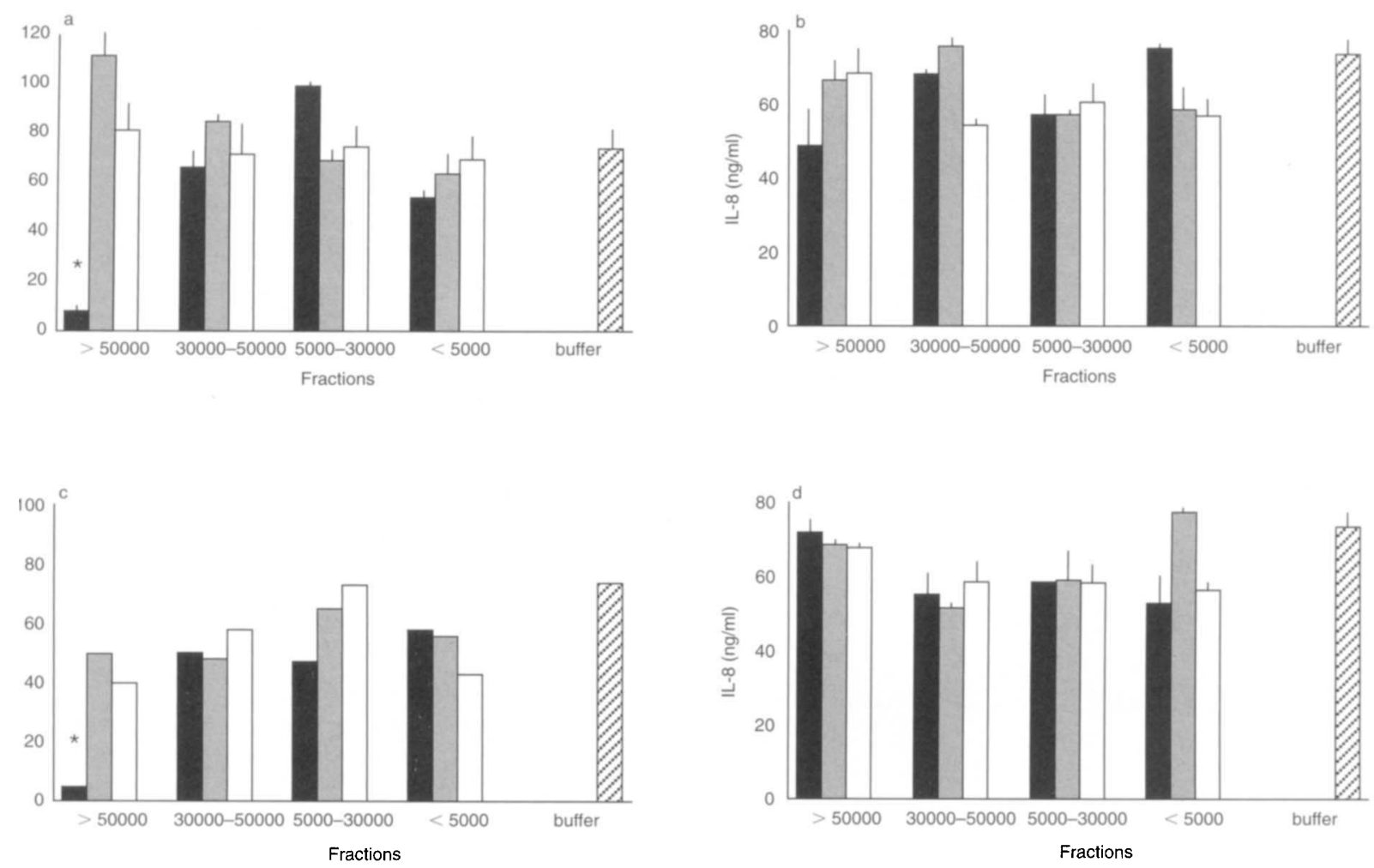

Fig. 5. Effects of $P$. aeruginosa culture supernate fractions on IL-8 release from human monocytes $\left(4 \times 10^{5}\right)$ left

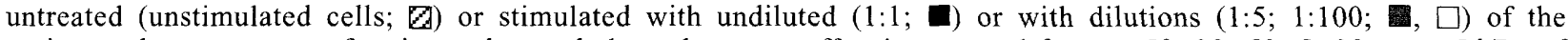
various culture supernate fractions whose whole mol. wt cut-off points ranged from $>50,30-50,5-30$, to $<5 \mathrm{kDa}$ of P. aeruginosa strains (a) PAO1, (b) PAO1 $\triangle \mathrm{SR}$, (c) PAO $\mathrm{PLCN}^{\circ}$ and (d) PAO1 $\triangle \mathrm{SRN}$. The culture supernates were isolated after $24 \mathrm{~h}$ and assayed for IL-8 by ELISA (triplicate determination). Data are mean and SD from three independent experiments; *significant difference compared to unstimulated cells, $\mathrm{p}<0.05$.

kDa

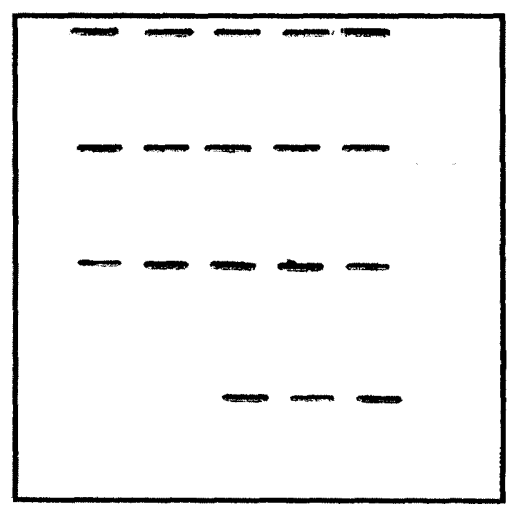

$1: 1 \quad 1: 2 \quad 1: 5 \quad 1: 10 \quad 1: 100$

\section{Dilution of culture supernate}

Fig. 6. Effects of $P$. aeruginosa PAO1 culture supernate fractions on IL-8 mRNA expression in human monocytes $\left(4 \times 10^{5}\right)$ stimulated with undiluted $(1: 1)$ or with dilutions $(1: 5 ; 1: 100)$ of the various culture supernate fractions whose mol. wt cut-off points ranged from $>50,30-50,5-30$, to $<5 \mathrm{kDa}$ ) of $P$. aeruginosa strain PAO1. The cell pellets were assayed for IL-8 mRNA expression by PCR. One representative experiment out of three is shown.

\section{Discussion}

P. aeruginosa infections play an important role in burns and sepsis as well as in CF [1-3]. The pathogenesis of lung injury in CF patients colonised by $P$. aeruginosa is especially associated with a massive accumulation of neutrophil granulocytes and neutrophil-mediated chronic pulmonary inflammation and destruction $[4,25]$. Arachidonic acid metabolites such as leukotriene $\mathrm{B}_{4}\left(\mathrm{LTB}_{4}\right)$ and 12-hydroxyeicosatetraenoic acid (12-HETE) as well as the cytokine IL-8 are potent chemotactic factors for neutrophils [20, 26, 27]. Although elevated $\mathrm{LTB}_{4}$ levels have been found in the sputum of CF patients, it is now established that IL-8 is probably the main cause of the excessive neutrophil recruitment and activation because of its long lasting effect [8-10]. It has been shown that PLC induces the chemotactically active $\mathrm{LTB}_{4}$ and 12-HETE $[2,20]$. Therefore, the hypothesis that PLC could contribute to inflammation by eliciting IL-8 seemed to be reasonable. Moreover, the description of two types of P. aeruginosa PLC, one haemolytic and the other non-haemolytic, opened up speculation as to the role of both types of PLC during infection. The present study used human monocytes, the main producer of IL-8.

The data clearly show a stimulating effect of PLC-H on 
IL-8. The effects on IL-8 release induced by PLC-H were observed at concentrations that induce only negligible amounts of $\mathrm{LTB}_{4}$. However, PLC concentrations that induced the generation of high amounts of $\mathrm{LTB}_{4}$ led to a decrease in IL-8 and IL-8 mRNA production [28]. These data were supported by the use of mutant $P$. aeruginosa PAOl strains capable of producing only one kind of PLC or none. In this regard, upregulation and inhibition of IL- 8 release were associated with a supernate fraction of $>50 \mathrm{kDa}$. Only strains that secrete PLC-H produced the high mol. wt inhibitor; the remaining supernate fractions with components $<50 \mathrm{kDa}$ did not trigger IL- 8 release from the cells. In a recent study, a $P$. aeruginosa culture supernate component of $<1 \mathrm{kDa}$ appeared to be a potent stimulator of IL-8 for epithelial cells [29]. This factor was not apparent under the conditions used in the present study; culture supernate components of mol. wt $<5 \mathrm{kDa}$ did not induce IL-8 release from human monocytes. Until now the interaction of PLC-N with inflammatory cells has not been elucidated. PAO1 mutant strains with a deleted haemolytic PLC gene exhibited a marked reduction in virulence when tested in the burn mouse model $[13,18]$. The present data support these findings and show that PLC-N failed to modulate IL-8 release.

These observations are not in contrast to the pathological picture observed in CF. While there is no doubt that PLC is important in initial $P$ aeruginosa infection because of inflammatory mediator release (enzymes, histamine, $\mathrm{LTB}_{4}$, oxygen metabolites) the role of $P$. aeruginosa $\mathrm{PLC}-\mathrm{H}$ in chronic infection must await further studies. $P$. aeruginosa isolates from CF patients at the chronic infection phase showed a decreased production of specific virulence determinants such as exotoxin A, exoenzyme S, phospholipase $C$ and lipase $[4,7]$. However, at present there is no information on the time course of $\mathrm{LTB}_{4}$ or IL-8 production in acute and chronic infection. From these results a pathogenic role may be ascribed to PLC-H at least for the acute phase of $P$. aeruginosa infection $[7,25]$. Previous studies have shown that antibodies to PLC are detected early and at high levels in CF patients $[14,15]$. It seems unlikely that biologically active $P$. aeruginosa PLC plays any role in chronic $P$. aeruginosa infection; however, there is no information about the neutralising capacity of these antibodies. Furthermore, PLC-antibody complexes may damage the host by $\mathrm{Fc}$ and complement-mediated pathophysiological reactions. The role of PLC-N for such a versatile pathogen as $P$. aeruginosa requires further studies.

W.K. was supported by the Bundeminister des Inneren.

\section{References}

1. Baltimore RS, Christie CD, Smith GJ. Immunohistopathologic localization of Pseudomonas aeruginosa in lungs from patients with cystic fibrosis. Implications for the pathogenesis of progressive lung deterioration. Am Rev Respir Dis 1989; 140: $1650-1661$

2. Bergmann $U$, Scheffer $J$, Köller $M$ et al. Induction of inflammatory mediators (histamine and leukotrienes) from rat peritoneal mast cells and human granulocytes by Pseudomonas aeruginosa strains from burn patients. Infect Immun 1989; 57: 2187-2195.

3. Döring G. Chronic Pseudomonas aeruginosa lung infection in cystic fibrosis patients. In: Campa M, Bendinelli M, Friedman $\mathrm{H}$ (eds) Pseudomonas aeruginosa as an opportunistic pathogen. New York, NY, Plenum Press. 1993: 245-273.

4. Hoiby N. Cystic fibrosis infection. Schweiz Med Wochenschr 1991; 121: 105-109.

5. Pier GB. Pulmonary disease associated with Pseudomonas aeruginosa in cystic fibrosis: current status of the hostbacterium interaction. J Infect Dis 1985; 151: 575-580.

6. Fick RB, Standiford TJ, Kunkel SL, Strieter RM. Interleukin-8 (IL-8) and neutrophil accumulation in the inflammatory airways disease of cystic fibrosis (CF). Clin Res 1991; 39: 292A (Abstract)

7. Wiener-Kronish JP, Sakuma T, Kudoh I et al. Alveolar epithelial injury and pleural empyema in acute $P$. aeruginosa pneumonia in anaesthetized rabbits. J Appl Physiol 1993; 75 : 1661-1669.

8. Bonfield TL, Ghnaim HA, Panuska JR, Konstan M, Berger M. Cytokines in the lungs of cystic fibrosis patients. FASEB Research Summer Conference, Vermont, 1993.

9. Konstan MW, Walenga RW, Hiliard KA, Berger M. Eicosanoid content of bronchoalveolar lavage fluid is markedly elevated in cystic fibrosis. Pediatr Pulm 1991; 6: 302-309.

10. Willems J, Joniau $M$, Cinque $S$, van Damme J. Human granulocyte chemotactic peptide (IL-8) as a specific neutrophil degranulator; comparison with other monokines. Immunology 1989; 67: 540-542.

11. Berka RM, Gray GL, Vasil ML. Studies on phospholipase C (heat-labile hemolysin) in Pseudomonas aeruginosa. Infect Immun 1981; 34: 1071-1074.

12. Meyers DJ, Berk RS. Characterization of phospholipase C from Pseudomonas aeruginosa as a potent inflammatory agent. Infect Immun 1990; 58: 659-666.

13. Vasil ML, Graham LM, Ostroff RM, Shortridge VD, Vasil AI. Phospholipase C: molecular biology and contribution to the pathogenesis of Pseudomonas aeruginosa. In: Homma JY, Tanimoto H, Holder IA, Hoiby N, Döring G (eds) Pseudomonas aeruginosa in human diseases. Antibiotics and Chemotherapy vol 44. Basel, Karger. 1991: 34-47.

14. Granström M, Ericsson A, Strandvik B et al. Relation between antibody response to Pseudomonas aeruginosa exoproteins and colonization/infection in patients with cystic fibrosis. Acta Paediatr Scand 1984; 73: 772-777.

15. Hollsing AE, Granström M, Vasil ML, Wretlind B, Strandvik B. Prospective study of serum antibodies to Pseudomonas aeruginosa exoproteins in cystic fibrosis. $J$ Clin Microbiol 1987; 25: 1868-1874.

16. Ostroff RM, Wretlind B, Vasil ML. Mutations in the hemolytic-phospholipase $\mathrm{C}$ operon result in decreased virulence of Pseudomonas aeruginosa PAol grown under phosphate-limiting conditions. Infect Immun 1989; 57: 1369-1373.

17. Ostroff RM, Vasil AI, Vasil ML. Molecular comparison of a nonhemolytic and a hemolytic phospholipase C from Pseudomonas aeruginosa. J Bacteriol 1990; 172: 5915-5923.

18. Shortridge VD, Lazdunski A, Vasil ML. Osmoprotectants and phosphate regulate expression of phospholipase C in Pseudomonas aeruginosa. Mol Microbiol 1992; 6: 863-871.

19. Graham LM, Vasil AI, Vasil ML, Voelkel NF, Stenmark KR. Decreased pulmonary vasoreactivity in an animal model of chronic Pseudomonas pneumonia. Am Rev Respir Dis 1990; 142: $221-229$.

20. König B, Jaeger K-E, König W. Induction of inflammatory mediator release (12-hydroxyeicosatetraenoic acid) from human platelets by Pseudomonas aeruginosa. Int Arch Allergy Immunol 1994; 104: 33-41.

21. Brunschwig E, Darzins A. A two-component T7 system for the overexpression of genes in Pseudomonas aeruginosa. Gene 1992; 111: 35-41.

22. Boyum A. Isolation of mononuclear cells and granulocytes from human blood. Isolation of mononuclear cells by one step centrifugation, and of granulocytes by combining centrifugation 
and sedimentation at $1 \mathrm{~g}$. Scand J Clin Lab Invest Suppl 97; 1968: $77-78$.

23. Tucker SB, Pierre RV, Jordon RE. Rapid identification of monocytes in a mixed mononuclear cell preparation. $J$ Immunol Methods 1977; 14: 267-269.

24. König B, Ceska M, König W. Effect of Pseudomonas aeruginosa on interleukin- 8 release from human phagocytes. Int Arch Allergy Immunol 1995; 106: 357-365.

25. Kindt GC, Gadek JE, Weiland JE. Initial recruitment of neutrophils to alveolar structures in acute lung injury. $J$ Appl Physiol 1991; 70: 1575-1585.

26. König W, Schönfeld W, Raulf M et al. The neutrophil and leukotrienes - role in health and disease. Eicosanoids 1990; 3 $1-22$.

27. Baggiolini $M$, Clark-Lewis I. Interleukin- 8 , a chemotactic and inflammatory cytokine. FEBS Lett 1992; 307: 97-101.

28. König B, König W. Induction and suppression of cytokine release (tumour necrosis factor-alpha; interleukin-6; interleukin $1 \beta$ ) by Escherichia coli pathogenicity factors (adhesins, alphahaemolysin). Immunology 1993; 78: 526-533.

29. Massion PP, Inoue H, Richman-Eisenstat $\mathrm{J}$ et al. Novel Pseudomonas product stimulates interleukin-8 production in airway epithelial cells in vitro. J Clin Invest 1994; 93: 26-32. 